\title{
The Food-Related Parenting Context: Associations with Parent Mindfulness and Children's Temperament
}

\author{
Melanie J. Zimmer-Gembeck ${ }^{1}$ (D) Anna McKay ${ }^{1} \cdot$ Haley J. Webb ${ }^{1}$ \\ (C) Springer Science+Business Media, LLC, part of Springer Nature 2019
}

\begin{abstract}
Objectives There were two objectives of this study. The first was to determine whether parents' dispositional mindfulness was associated with food-related parenting, including more support and structure and less coercion and chaos. The second was to consider children's temperament and food-related parenting, with a focus on reactivity and regulation. Parents' beliefs and concerns about body and child weight and demographic factors were also considered.

Methods Caregivers of children aged 4-8 years $(N=167,94 \%$ female $)$ completed measures of food-related parenting, dispositional mindfulness, children's temperament (surgency, negative affectivity, and effortful control), parents' concern about child's weight, and parents' body dissatisfaction. Parents also reported their children's age, gender, family income, and education.

Results As hypothesized, parents higher in mindfulness reported more food-related supportiveness and structure and less foodrelated coerciveness and chaos; most associations were significant even after accounting for children's temperament and all other measures. For temperament, children's effortful control was associated with higher levels of parent supportiveness and structure, whereas negative affectivity was positively associated with coerciveness and chaos. Although parents' body dissatisfaction and concerns about their children's weight were usually correlated with food-related parenting, few associations remained significant in the multivariate models. Children's surgency and demographic factors were not associated with food-related parenting.

Conclusions Parents' mindfulness and children's negative affectivity and effortful control, which we argued reflect reactivity and regulation, were uniquely associated with parents' food-related supportiveness, structure, coerciveness, or chaos. Future research should examine bidirectional pathways to better isolate the direction of effects and pinpoint potential intervention targets.
\end{abstract}

Keywords Food-related parenting $\cdot$ Temperament $\cdot$ Negative affect $\cdot$ Surgency $\cdot$ Effortful control $\cdot$ Mindfulness

About one in every three children has been classified as overweight or obese and the rate is increasing even in children under 5 years (De Onis et al. 2010). In addition about $90 \%$ of children in the USA and Australia consume more than the maximum discretionary allowance for fat and sugar (Johnson et al. 2017; Krebs-Smith et al. 2010) and only a very small proportion of children, even young children, meet the standard recommended daily vegetable intake (Webb et al. 2018). Parents often struggle to find ways to reduce their children's desire for and consumption of sugary and fatty (i.e. snack)

Melanie J. Zimmer-Gembeck m.zimmer-gembeck@griffith.edu.au

1 School of Applied Psychology, Griffith University, Gold Coast, Queensland, Australia foods and engage their children in healthier eating. Such struggles can be important because eating patterns set in childhood often continue into adulthood, obese children are at risk of many lifestyle-related health problems in adulthood, and early feeding practices are associated with later overweight status in children (De Onis et al. 2010; Haszard et al. 2019)

Parenting is complex, but at its core most parenting practices are aimed at socializing children's adaptive and prosocial behaviors and helping children to self-regulate their emotions, cognitions, and behavior to stay safe, healthy, and productive, form good relationships, and reach their life goals. This applies when considering parenting and children's eating and weight, with a fairly large empirical literature available that has examined the adaptability of particular parenting practices, in general or specific to feeding, for children's selfregulation of their energy intake and their weight (for reviews see DeCosta et al. 2017; Mitchell et al. 2013; 
Vaughn et al. 2016). Most recent reviews conclude that parents can have an influence on young children's energy intake and weight by guiding food availability and eating behavior. Generally, parents who use an authoritative parenting style, marked by high warmth combined with demandingness or structure, are reported to have children with more adaptive eating behaviors or a healthier diet (Mitchell et al. 2013; Sleddens et al. 2014; Vollmer and Mobley 2013). In addition, the food-related parenting context, or the emotional climate of parent-child feeding interactions, may play a significant role in child eating behaviors (Joyce and Zimmer-Gembeck 2009). However, there are individual characteristics of parents and children that may be related to food-related parenting practices (Coatsworth et al. 2015; Gouvela et al. 2019; Leung et al. 2014). Identifying these dispositional factors, which predict more beneficial ways of food-related parenting, could be useful as a guide to the design of programs that assist parents to adaptively and successfully manage their children's food choices and eating behaviors, as well as assisting with parenting related to preparing and providing food within the family.

General parental styles, most especially responsiveness and demandingness of parents with their children, have been examined as correlates of children's eating and weight. In this research, responsiveness includes warm interactions, as well as attention, understanding, and responsiveness to children's needs, whereas demandingness is used to refer to behaviors that communicate high expectations of parents and conforming to these expectations by children (Lopez et al. 2019; Yavuz and Selcuk 2018). Parental styles have been described as markers of the overall family emotional climate (Darling and Steinberg 1993). In the handful of studies that have examined associations of general parenting styles with children's eating or weight, parenting style has been associated with children's healthier eating or weight outcomes (Shloim et al. 2015). For example, authoritarian parenting style (low warmth and high demandingness) has been associated with lower scores on a healthy eating index considering sugar, fruits, and vegetables (Lopez et al. 2019) and, in a separate study, children (age 45 to 80 months) who were overweight were almost five times as likely as normal weight children to have mothers with an authoritarian parenting style (Yavuz and Selcuk 2018).

Turning to parenting practices, these have been described as goal directed behaviors that are specific to particular situations (Hennessy et al. 2010; Vollmer and Mobley 2013). For example, in the research on parenting and children's weight and eating, the focus has usually been placed on parental feeding practices, including strategies that control what, how much, or when children eat (Lopez et al. 2019; Ventura and Birch 2008). Parent feeding practices have most often been defined to include parental pressure to eat, and restriction or monitoring of child eating (Rollins et al. 2014; Yavuz and Selcuk 2018). Although the findings are not always consistent across studies, parental feeding restriction and pressure to eat have been associated with poorer children's dietary intake (e.g., Mitchell et al. 2013). Such an association is argued to be explained by children's internal regulation of eating, with restriction and pressure undermining regulation and perpetuating more problematic eating behaviors (Black and Aboud 2011; Rollins et al. 2015). In addition, when examined, general parenting styles have only weak associations with parent feeding practices (Lopez et al. 2019) with the associations appearing to be strongest between authoritarian parenting (low warmth and high demandingness) and higher use of feeding restriction and pressure to eat (Yavuz and Selcuk 2018).

One approach to integrating theory on general parenting styles with parental feeding practices has been encapsulated in the Parent Socioemotional Context of Feeding Questionnaire (PSCFQ; Zimmer-Gembeck et al. 2019a). The PSCFQ was founded on Self-Determination Theory (SDT; Deci and Ryan 1985; Ryan and Deci 2000) and designed to assess parenting dimensions known to be associated with children's self-regulation and well-being (Deater-Deckard et al. 2012; Joussemet et al. 2008). In particular, SDT suggests that parents who help children to meet their needs for relatedness, competence, and autonomy via parenting behaviors will have children who are more likely to engage positively with their parents and to internalize their parents' values, eventually resulting in children's adaptive self-regulation of behavior (Grolnick et al. 1997; Skinner et al. 2005). This is also relevant in the eating and feeding domain, given that parents usually strive for their children to internalize healthy eating choices and enact them with little external regulation (e.g., rewards or punishments, parental monitoring; Ng et al. 2012). In SDT, multiple parenting dimensions relevant to promoting children's internalization and self-regulation are identified and all have been represented in the PSCFQ. These include parental supportiveness (including warmth and autonomy support) and structure identified as dimensions that facilitate children's internalization and self-regulation of behavior, and parental coerciveness (hostility and coercion) and chaos as those dimensions that undermine internalization and self-regulation (see Chiang and Padilla 2012; Frankel et al. 2018; Girelli et al. 2016; Joyce and Zimmer-Gembeck 2009).

The PSCFQ was designed specifically for children age 4 to 8 years. During this age, eating remains primarily under the regulation of adults, but children are beginning to regulate themselves across a number of domains of behavior and this includes food selection and energy intake (Parent et al. 2016). Moreover, children demonstrate continuity in their appetitive traits from age 4 years into middle to late childhood (Ashcroft et al. 2008), and children in the 4 to 8 age range are expected to increase their daily calorie intake (US Dept. of Health and Human Services and US Depart. of Agriculture 2015). As such, the challenges of food-related parenting are expected 
to change alongside child age and will differ to the problems faced for parent of infants/toddlers. Yet, children age 4 to 8 are not expected to be afforded the same autonomy in their food choices as would be found during the adolescent transition (age 9 and up), making the challenges of this age also different from food-related parenting of older children and adolescents.

Given the difficulties faced by parents of young children, many programs exist to support healthy food-related choices and to teach additional skills when managing children's behavior in and outside of the eating context. A promising new direction in parenting support programs is the integration of training in mindfulness practices. Theory suggests that promoting mindfulness could be useful, because it has been found to be a correlate of more positive parenting in general (Coatsworth et al. 2015; Harnett and Dawe 2012). Kabat-Zinn (2003) described mindfulness as "the awareness that emerges through paying attention, on purpose, in the present moment, and non-judgmentally, to the unfolding of experience moment to moment" (p. 145). There is evidence demonstrating various benefits of mindfulness among adults (Keng et al. 2011). For example, when mindfulness is conceptualized as a dispositional trait or tendency, it has been defined to include observing sensations, thoughts, and feelings; describing sensations, thoughts, and feelings; acting with present-moment awareness; nonjudgment of inner experience; and nonreactivity to inner experience (Baer et al. 2006). Such dispositional mindfulness has been related to better psychological functioning and fewer symptoms of depression and anxiety (Hambour et al. 2018; Keng et al. 2011) and has been associated with greater life satisfaction and self-esteem (Pepping et al. 2013).

Extending this to the parenting domain, there are three bodies of literature that suggest mindfulness could be an asset for positive food-related parenting. First, dispositional mindfulness has been found to covary with more positive parenting beliefs, as well as with a more positive parenting style and warmer and more supportive parenting practices, as well as better parent-child relationship quality, less parenting stress (Coatsworth et al. 2015), and fewer child symptoms of mental health and behavioral problems (Parent et al. 2016). Also, in the only study to date we could locate, mindful parenting (e.g., listening with full attention, emotional awareness of the child) was associated with parental feeding practices of more monitoring but less restriction and use of food as reward (Gouvela et al. 2019). Mindfulness has now been incorporated into parenting programs for children with disruptive behaviors (Dumas 2005) and externalizing disorders such as ADHD (e.g., Singh et al. 2010) with the growing evidence that mindfulness can assist in more positive parent-child relationships. These studies, although at times limited by small sample sizes and a lack of comparison groups, have demonstrated potential benefits of mindfulness enhancement for parenting quality (Harnett and Dawe 2012).
Second, mindfulness has been associated with a greater capacity for emotion regulation (Hambour et al. 2018; Roemer, Williston, \& Rollins et al. 2015), with compelling information from neuropsychological investigation supporting this by demonstrating enhanced prefrontal cortical activity suggesting better regulation and reduced stress reactivity among those higher in dispositional mindfulness (Taren et al. 2013). Moreover, emotion regulation has been associated with warmer, more supportive, and less hostile parenting practices (Zimmer-Gembeck et al. 2019b). Given this evidence, we expected that an elevated level of mindfulness should allow parents to maintain emotional stability resulting in more supportive interactions with their children in the eating domain, while also maintaining guidelines and providing a structured, predictable food-related home environment. Also, individuals higher in dispositional mindfulness are less judgmental of themselves and others and are better able to witness present-moment experiences. Thus, parents higher in mindfulness might be able to draw on these resources to minimize coercive parent-child interactions (which can involve judgment and a focus on past bad behavior) and avoid a chaotic home life when it comes to preparing and providing food and managing children's eating preferences and problems.

Third, mindfulness has been associated with higher body satisfaction and fewer eating disorder symptoms in women (Dijkstra and Barelds 2011; Pepping et al. 2015). There has been a great deal of interest and attention on mindfulnessbased eating disorder programs with some success (WandenBerghe et al. 2010). Therefore, a capacity such as dispositional mindfulness, which seems to afford better personal management of eating behavior, should be a resource when engaging in parenting behaviors related to managing food availability and consumption for the entire family. This also suggests that control for weight concerns - personal and for the childwould be important covariates in any study of mindfulness and food-related parenting.

Children's temperament has also been shown to be a correlate of parenting practices (e.g., Leung et al. 2014). To consider temperament, we relied here on Rothbart's temperament model to focus specifically on children's reactivity as well as their capacity for regulation (Rothbart et al. 2000; Rothbart 2007). In this theory, reactivity and regulation are primarily assessed as surgency, negative affect, and effortful control. Surgency is the tendency to be active and engage in impulsive behavior. Children who score high in surgency often display behavioral difficulties such as low frustration tolerance and higher aggression levels. Negative affectivity is a predisposition to experience negative affective states (anger/frustration, sadness, social fear, low soothability) especially when confronting potentially aversive stimuli. Thus, negative affectivity reflects high reactivity. Effortful control is linked to executive functioning and is the ability to control or regulate attentional processes and behavior (Rothbart et al. 2011). 
Temperament has been implicated in children's energy intake, energy expenditure, and obesity risk partly because it can evoke certain responses from caregivers (Anzman-Frasca et al. 2012; Leung et al. 2014). The temperamental traits most likely implicated are low self-regulation and low soothability, and high emotionality and negative affectivity, which are all tapped when including measures of surgency and negative affectivity (Haycraft et al. 2011; Tan and Holob 2011). For example, in one longitudinal study (Boles et al. 2013), parents were more likely to use pressure to eat or restriction when they perceived their offspring to have a difficult temperament marked by surgency and negative affectivity. In addition, children high in surgency have been found to have more desires to eat and to be more likely to overeat in response to external cues (Leung et al. 2014). In this same study, children higher in negative affectivity were found to tantrum when denied food and were less likely to eat when not hungry. Thus, having a child higher in surgency and negative affectivity would seem to make it more difficult for parents to provide a positive foodrelated context or support and structure and to avoid coercion and chaotic parent-child interactions.

It is less clear how young children's effortful control relates to eating behavior; some studies have reported no significant associations (e.g., Leung et al. 2014), but others have reported a link between constructs related to effortful control, such as executive control, and eating behavior (e.g., Pieper and Laugero 2013). Nevertheless, children higher in effortful control are defined to have more self-regulatory capacity (Rothbart et al. 2000) and multiple studies have shown links between children's self-regulation and positive parenting practices, as well as poorer self-regulation and overweight and obesity in older children and adolescents (e.g., Godefroy et al. 2016; Von Suchodoletz et al. 2011).

In summary, the current study was designed to understand how parents' dispositional mindfulness and the reactivity and regulatory capacity (i.e., temperament) of young children (age 4 to 8 years) are related to multiple dimensions of the food-related parenting context. Together, our focus on mindfulness and temperament emphasizes the role of self-regulation of parents and children in food-related parenting. Our first hypothesis was that parent mindfulness will be associated with more food-related parental supportiveness and structure and less coerciveness and chaos. Second, we hypothesized negative associations of child surgency and negative affectivity with food-related parent supportiveness and structure and positive associations with foodrelated parent coerciveness and chaos. Finally, we hypothesized positive associations of child effortful control with food-related parent supportiveness and structure and negative associations with food-related parent coerciveness and chaos. Because parents' concerns and body dissatisfaction are likely to be correlates of their food-related parenting and mindfulness, and because child age and sex, as well as parent education and income, have been found to be associated with parenting and eating behavior in past research (Blissett et al. 2006; Hendy and Williams 2012), we controlled for these variables in the multivariate analyses.

\section{Method}

\section{Participants}

The participants were 167 parents (94\% female, $M_{\text {age }}=39.5$ years, $S D_{\text {age }}=6.2$ years). All responded about their 4 - to 8year-old children (or selected to respond about one of their children in the age range, if there was more than one in the age range within the family; $53 \%$ female, $M_{\text {age }}=5.9, S D_{\text {age }}=1.5$ ). Most $(91 \%)$ of the parents reported holding primary responsibility for food preparation and feeding of their children. For household income, 5\% reported less than AUD\$20,000 (US\$14,000), $14 \%$ reported AUD $\$ 20,000$ to $\$ 50,000$ (US\$14,000 to $\$ 35,000), 35 \%$ reported AUD\$50,000 to $\$ 100,000$ (US\$35,000 to $\$ 70,000$ ), and $47 \%$ reported a household income of $\$ 100,000$ per year or higher (US\$70,000 or higher). For respondent education, $6 \%$ reported high school or less education, $18 \%$ reported vocational training beyond high school, and $76 \%$ reported some university education. Income and education were higher than the Australian national statistics (Australian Bureau of Statistics 2015). Of the respondents, $70 \%$ reported they were married, $15 \%$ were in a de facto relationship (living together but not married), and $15 \%$ were separated or divorced.

An additional 54 parents completed part of the survey, with 31 respondents completing only the first measure (of parent feeding practices) and 23 completing all measures except for child temperament (the last measure presented in the survey). To determine if these participants were different from the 167 other parents included in this study, we used multiple imputation to estimate 20 sets of complete data for all 221 parents. Pooled results across these 20 datasets were examined. These results with the full set of 221 parents did not differ from the results with the 167 parents with complete data. Thus, the results below include data from these 167 parents only. With a sample size of 167 and $\alpha$ set to 0.05 , we had more than 0.95 power to detect even a small effect size $(0.10)$ for each regression coefficient $t$ test in a model with 10 predictors.

\section{Procedure}

The Griffith University Human Research Ethics Committee approved the study. Participants were recruited using three methods. First, study information and the online survey link were shared via three Australian parenting groups on Facebook and 48 parents participated. Second, six local preschools and primary schools shared study information and the survey link in their newsletter and/or via email, which attracted 31 participants. Third, the study was advertised to 
university staff and students via an online newsletter, which attracted another 88 participants.

\section{Measures}

Food-Related Parenting The Parent Socioemotional Context of Feeding Questionnaire (PSCFQ; Zimmer-Gembeck et al. 2019a) was used to assess food-related parenting. The PSCFQ included 32 items designed for parents of children aged 4 to 8 years. The PSCFQ comprises four subscales of supportiveness, structure, coerciveness, and chaos. The supportiveness subscale includes warmth and autonomy supportive parenting; assessing parents' expression of kindness, enjoyment, and regard around mealtimes; and the extent to which parents' support their children to make healthy eating choices by providing appropriate options (10 items; e.g., "When it comes to selecting food and feeding my child, I let my child know I respect his/her likes and dislikes"). The structure subscale assesses parents' ability to provide expectations for behavior, maintain consistent guidelines, and set appropriate limits around eating (six items: e.g., "When it comes to selecting food and feeding my child, I tell or show the behavior that is expected at meal and snack times"). The coerciveness subscale assessed parents' hostility/rejection and coerciveness (10 items; e.g., "When it comes to selecting food and feeding my child, I often have to raise my voice"). The chaos scale assessed inconsistent, unpredictable, and arbitrary parenting around mealtimes (six items; e.g., "When it comes to selecting food and feeding my child, I can be unpredictable in how I will react"). All items had responses ranging from 1 (extremely untrue) to 6 (extremely true). Items were averaged to form subscale scores, and higher scores indicated greater use of the food-related parenting dimension. In the current study, Cronbach's $\alpha$ was 0.81 for supportiveness, 0.88 for structure, 0.91 for coerciveness, and 0.79 for chaos.

\section{Parents' Mindfulness The Five Facet Mindfulness} Questionnaire (Baer et al. 2006) is a 39-item measure of dispositional mindfulness. Items assess observing sensations, thoughts, and feelings; describing sensations, thoughts, and feelings; acting with present-moment awareness; nonjudging of inner experience; and nonreactivity to inner experience. Example items include "In difficult situations, I can pause without immediately reacting" (nonreactivity) and "When I'm walking, I deliberately notice the sensations of my body moving" (observing). Response options range from 1 (extremely untrue) to 6 (extremely true). After reversing some items, a total mindfulness score was calculated by averaging all items (Cronbach's $\alpha=0.93$ ).

Children's Temperament The Child Behavior QuestionnaireVery Short Form (Putman and Rothbart 2006) is a 36-item parent report assessment of children's temperament (ages 3 to 8 years). The questionnaire captures three dimensions of surgency, negative affect, and effortful control. Informants rate their child's likely reaction in a variety of situations. Example items include "My child gets quite frustrated when prevented from doing something s/he wants to do" and "My child likes rough and rowdy games." Responses ranged from 1 (extremely untrue of my child) to 6 (extremely true of my child). Averaging relevant items (eight items were reverse scored) formed total scores for temperamental dimensions. Higher scores indicated higher levels of temperamental dimensions. In the current study, Cronbach's $\alpha$ was 0.79 for surgency, 0.81 for negative affect, and 0.70 for effortful control.

Parents' Body Dissatisfaction The Body Dissatisfaction subscale of the Eating Disorder Inventory (Garner et al. 1983) measured caregiver body dissatisfaction. The subscale had nine items rated from 1 (always) to 6 (never). Five items were reverse scored before all items were averaged to form a total score. Higher scores indicated greater body dissatisfaction. Example items include "I think my stomach is too big" and "I feel satisfied with the shape of my body (reverse scored)." In the current study, Cronbach's $\alpha$ was 0.92 .

Parents' Concern About Child Weight The concern subscale of the Child Feeding Questionnaire (Birch et al. 2001) measured parents' concern about child eating and weight. The concern subscale included three items (e.g., "How concerned are you about your child becoming overweight?'). This subscale has a 6-point response scale ranging from 1 (unconcerned) to 6 (very concerned). In the current study, Cronbach's $\alpha$ was 0.73 , and items were averaged to form a total concern score.

\section{Data Analyses}

After examining the $M$ s and SDs of all variables, Pearson's correlations were computed to test associations between all variables. Next, four hierarchical linear regressions were estimated to examine the association of each food-related parenting dimension with parents' mindfulness after adjusting for children's temperament, parents' concern for child weight, and responding parents' body dissatisfaction, education, and household income. In each regression, one food-related parenting dimension was the dependent variable with the independent variables (IVs) of child age and sex, parents' education, family income, and parents' concerns and body dissatisfaction entered at step 1, child temperament at step 2, and parents' mindfulness at step 3. We entered the IVs in this order because our primary study aim was to test whether parents' dispositional mindfulness was a correlate of food-related parenting after accounting for (1) demographics (child age and sex, parent education, family income), (2) parent concerns about their children's weight and their own body 
dissatisfaction, and (3) any associations of children's own temperamental dispositions. Thus, mindfulness was entered in step 3. Our secondary interest was to test the associations of children's temperament with food-related parenting after controls for demographic information and parents' body dissatisfaction and concerns. To do this, we entered temperament in step 2. A Bonferroni correction was applied to adjust for the four regressions conducted, resulting in an alpha of 0.0125 .

All but two measures approximated a normal distribution (skew ranged from $|0.08|$ to $|0.36|)$; the two exceptions were food-related parent structure (skew $=-1.06$ ) and concern about child weight (skew $=1.17$ ). No outlier was detected that had an excessive leverage on the results. Given that there were only minor departures from the assumptions of regression analysis, no variables were transformed and all 167 respondents were maintained in all analyses. No problems with multicollinearity were identified (e.g., tolerance values were all above 0.90 except for mindfulness with a tolerance of 0.74 , which are indications of low multicollinearity among the independent variables; Tabachnick and Fidell 2001).

\section{Results}

\section{Descriptive Statistics and Zero-Order Correlations}

$M \mathrm{~s}, S D \mathrm{~s}$, and correlations between variables are presented in Table 1. As hypothesized (hypothesis 1), parents' dispositional mindfulness was positively associated with parents' foodrelated supportiveness and structure and negatively associated with coerciveness and chaos. Also, as expected, two of the child temperament variables, negative affectivity and effortful control, were associated with food-related parenting. More specifically, children's negative affectivity was positively associated with coerciveness and chaos (hypothesis 2); children's effortful control was positively associated with supportiveness and structure (hypothesis 3 ). Unexpectedly, child surgency had no significant relationship with the foodrelated parenting dimensions. Finally, parents' dispositional mindfulness had a significant negative relationship with the child temperament dimension of negative affect, and a positive relationship with effortful control.

\section{Food-Related Parenting, Child Temperament, and Dispositional Mindfulness}

Parents' body dissatisfaction, concerns about child weight, education, and income, entered at step 1, explained little variance in parental supportiveness $(1 \%)\left(F_{(6,160)}=0.31, p=.93\right)$ (see Table 2). The entry of child temperament variables (surgency, negative affect, and effortful control) at step 2 explained an additional $18 \%$ of the variance $\left(\Delta F_{(3,157)}=11.61\right.$, $p<.001$ ), with only effortful control significantly (positively) associated with supportiveness. At step 3, parents' dispositional mindfulness was entered and accounted for an additional 3\% of the variance $\left(\Delta F_{(1,156)}=6.63, p=.01\right)$, and mindfulness was positively associated with more food-related supportive parenting. In the final model, child effortful control and parental mindfulness were each uniquely and positively associated with food-related parental supportiveness.

For food-related parental structure, parents' concerns accounted for $9 \%$ of the variance $\left(F_{(6,160)}=2.58, p=\right.$ $.02)$, with concern about child weight significantly associated with less parental structure (see Table 2). Note, that this step was not significant when the Bonferroni correction was applied $(p<.0125)$. Child temperament was added at step 2 , and explained an additional $6 \%$ of the variance $\left(\Delta F_{(3,157)}=4.28, p<.001\right)$, with children's effortful control significantly associated with more foodrelated parental structure. At step 3, mindfulness was added but was not significantly associated with parents' structure. After the final step of the model, parental structure at mealtimes was negatively associated with parental concern about child weight and uniquely and positively associated with child effortful control.

For food-related parenting coerciveness, demographic measures and parents' concerns entered at step 1 accounted for $6 \%$ of the variance $\left(F_{(6,160)}=1.72, p=.12\right)$ (see Table 3 ). Parents who were more dissatisfied with their bodies reported more food-related coerciveness. Child temperament explained an additional $7 \%$ of the variance at step $2\left(\Delta F_{(3,157)}=4.30, p\right.$ $<.01$ ), with parent body dissatisfaction and children's negative affectivity significantly associated with more parental coerciveness. When parents' mindfulness was added at step 3, the additional variance explained was $7 \%\left(\Delta F_{(1,156)}=14.21\right.$, $p<.001$ ), and mindfulness was significantly negatively associated with coerciveness. After the final step of the model, children's negative affectivity and food-related parental mindfulness were each uniquely associated with elevated parents' food-related coerciveness.

For food-related chaos, the variables entered in step 1 accounted for $9 \%$ of the variance in chaos $\left(F_{(6,160)}=2.56\right.$, $p=.02$ ), and both body dissatisfaction and parents' concerns about their children's weight were associated with more chaotic food-related parenting (see Table 3). Note, that this step was not significant when the Bonferroni correction was applied $(p<.0125)$. When child temperament was added at step 2, $4 \%$ additional variance was explained $\left(\Delta F_{(3,157)}=2.33, p=.08\right)$, and children's negative affectivity was significantly associated with more food-related parenting chaos, as was parents' body dissatisfaction. The addition of dispositional mindfulness in step 3 explained an additional $14 \%$ of variance $\left(\Delta F_{(1,156)}=30.87, p<\right.$ $.001)$, and mindfulness was the significant correlate of chaotic food-related parenting, with parents higher on mindfulness reporting less chaos. 
Table 1 Means, standard deviations, and zero-order correlations between study variables $(N=167)$

\begin{tabular}{|c|c|c|c|c|c|c|c|c|c|c|c|c|c|c|}
\hline & & 1 & 2 & 3 & 4 & 5 & 6 & 7 & 8 & 9 & 10 & 11 & 12 & 13 \\
\hline 1 & P support & - & & & & & & & & & & & & \\
\hline 2 & $\mathrm{P}$ structure & $.30 * *$ & - & & & & & & & & & & & \\
\hline 3 & $\mathrm{P}$ coercive & -.08 & .10 & - & & & & & & & & & & \\
\hline 4 & $\mathrm{P}$ chaos & -.01 & $-.26^{* *}$ & $.40 * *$ & - & & & & & & & & & \\
\hline 5 & P mindfulness & $.24 * *$ & $.22 * *$ & $-.40 * *$ & $-.47 * *$ & - & & & & & & & & \\
\hline 6 & C surgency & -.12 & -.05 & -.07 & -.01 & .13 & - & & & & & & & \\
\hline 7 & $\mathrm{C}$ neg affect & -.03 & -.14 & $.27 * *$ & $.28 * *$ & $-.35^{* *}$ & -.09 & - & & & & & & \\
\hline 8 & C effort control & $.38 * *$ & $.26^{* *}$ & -.11 & -.04 & $.23 * *$ & -.08 & -.15 & - & & & & & \\
\hline 9 & PCC weight & -.04 & $-.23 * *$ & .03 & $.17 *$ & -.10 & .08 & $.20 * *$ & .01 & - & & & & \\
\hline 10 & P Body dis & -.03 & -.13 & $.21 * *$ & $.22 * *$ & $-.35^{* *}$ & .03 & $.21 * *$ & -.09 & .08 & - & & & \\
\hline 11 & $\mathrm{P}$ education & .02 & .12 & -.02 & -.13 & $.20 * *$ & .06 & -.12 & .10 & -.07 & -.08 & - & & \\
\hline 12 & Family income & -.05 & .12 & .07 & -.10 & .07 & -.07 & $-.18^{*}$ & $.15^{*}$ & -.05 & -.02 & $.29 * *$ & - & \\
\hline 13 & $\mathrm{C}$ age & .06 & .00 & -.10 & .08 & .11 & .07 & .01 & -.01 & .00 & .03 & -.11 & .08 & - \\
\hline \multirow[t]{3}{*}{14} & $C \operatorname{sex}$ & -.04 & -.09 & -.04 & -.03 & -.02 & $-.16^{*}$ & .00 & $.23 * *$ & .15 & -.06 & .03 & .06 & -.07 \\
\hline & $M$ & 4.6 & 4.6 & 3.1 & 3.0 & 4.1 & 3.5 & 3.2 & 4.2 & 2.1 & 3.6 & - & - & - \\
\hline & $S D$ & 0.7 & 0.8 & 1.0 & 0.9 & 0.6 & 0.7 & 0.7 & 0.5 & 1.1 & 1.1 & - & - & - \\
\hline
\end{tabular}

$* p<.05$

$* * p<.01$

Note. $P$ parent, $C$ child, $P C C$ weight parent concern for child weight, $P$ Body dis parent body dissatisfaction.

Parent education was recoded as $0=$ high school only or vocational training, $1=$ some university or university graduate. Child sex was coded $0=$ boy, $1=$ girl ( 1 child was reported as "other" and was assigned the average of .5)

\section{Discussion}

Focusing on parents of children aged 4 to 8 years old, we investigated whether dispositional mindfulness, defined as parents' capacity to attend to and recognize emotions and be in the present moment without judgment, would be associated with more supportive and structured, and less coercive and chaotic, food-related parenting. In addition, we tested whether young children's temperament, including surgency and negative affectivity (as measures of reactivity), and effortful control (as a measure of regulation), were associated with foodrelated parenting. We examined these associations before and after accounting for the role of parents' body dissatisfaction, parents' concerns about their children's weight, parents' education level and income, and child age and sex.

\section{Parents' Mindfulness and Food-Related Parenting}

Initial correlational analyses supported our hypothesis that parents' mindfulness would be associated with food-related parenting practices; such an association was found across all food-related parenting dimensions, including the positive dimensions of supportiveness and structure and the negative dimensions of coerciveness and chaos. Parents who reported more mindfulness were higher in supportiveness and structure, reporting more praise, encouragement, fun with food, encouragement of children's expression of food choices, clear guidelines, and consistent expectations. Parents who reported being more mindful were also lower in food-related coerciveness and chaos, so they reported that they were less pushy and controlling about eating behaviors and that they minimized inconsistencies in the food selected, prepared, and consumed. In multivariate analyses, three of these aspects of food-related parenting - all but structure - remained associated with mindfulness even after accounting for any influence of children's temperament, parents' body dissatisfaction, parents' concerns about their children's weight, parents' education level and income, and child age and sex.

Reasoning from these results, parents' dispositional mindfulness, including observation and nonreactivity to inner experience and acting with awareness of the present moment, seems to be an attribute or learned skill that promotes more positive food-related interactions with children. This might be explained by links found between mindfulness and better emotional regulation in past research (Bögels and Restifo 2014; Hambour et al. 2018; Roemer et al. 2015). It may be that it is the accompanying enhanced emotion regulation capacity that co-occurs with dispositional mindfulness that assists parents to be more supportive, less frustrated, and less emotionally reactive during interactions with children that involve feeding and eating. Although not directly tested here, other research and theory suggests that these food-related parenting practices could, in turn, be associated with children's consumption of healthier foods and better self-regulation of 
Table 2 Unique associations of positive food-related parenting with child temperament and parental mindfulness $(N=167)$

\begin{tabular}{|c|c|c|c|c|c|c|c|c|}
\hline & \multicolumn{4}{|c|}{ Parent Supportiveness } & \multicolumn{4}{|c|}{ Parent Structure } \\
\hline & $\Delta R^{2}$ & $\beta$ & $B(\mathrm{SE} B)$ & $p$ value & $\Delta R^{2}$ & $\beta$ & $B(\mathrm{SE} B)$ & $p$ value \\
\hline Step 1 & 0.01 & & & & $0.09 *$ & & & \\
\hline Child age & & 0.07 & $0.03(0.04)$ & .385 & & -0.01 & $0.00(0.04)$ & .934 \\
\hline Child sex & & -0.03 & $-0.04(0.11)$ & .700 & & -0.07 & $-0.12(0.13)$ & .356 \\
\hline Parent education & & 0.04 & $0.04(0.09)$ & .661 & & 0.07 & $0.10(0.11)$ & .346 \\
\hline Family income & & -0.06 & $-0.05(0.07)$ & .437 & & 0.10 & $0.10(0.08)$ & .218 \\
\hline Parent body dissatisfaction & & -0.03 & $-0.02(0.05)$ & .670 & & -0.11 & $-0.08(0.06)$ & .163 \\
\hline Concern for child's weight & & -0.03 & $-0.02(0.05)$ & .704 & & $-0.21 * *$ & $-0.17(0.06)$ & .007 \\
\hline Step 2 & $0.18 * * *$ & & & & $0.07 * *$ & & & \\
\hline Child age & & 0.07 & $0.03(0.03)$ & .331 & & -0.01 & $-0.01(0.04)$ & .914 \\
\hline Child sex & & -0.14 & $-0.20(0.10)$ & .062 & & -0.14 & $-0.23(0.13)$ & .084 \\
\hline Parent education & & 0.00 & $0.00(0.08)$ & .989 & & 0.04 & $0.06(0.11)$ & .575 \\
\hline Family income & & -0.12 & $-0.10(0.06)$ & .123 & & 0.06 & $0.06(0.08)$ & .434 \\
\hline Parent body dissatisfaction & & 0.00 & $0.00(0.05)$ & .999 & & -0.08 & $-0.06(0.06)$ & .293 \\
\hline Concern for child's weight & & -0.02 & $-0.01(0.05)$ & .806 & & $-0.20 *$ & $-0.16(0.06)$ & .010 \\
\hline Child surgency & & -0.12 & $-0.12(0.08)$ & .116 & & -0.03 & $-0.04(0.10)$ & .687 \\
\hline Child negative affective & & 0.01 & $0.01(0.07)$ & .931 & & -0.03 & $-0.04(0.09)$ & .703 \\
\hline Child effortful control & & $0.42 * *$ & $0.55(0.10)$ & $<.001$ & & $0.27 * *$ & $0.44(0.13)$ & .001 \\
\hline Step 3 & $0.03 *$ & & & & 0.01 & & & \\
\hline Child age & & 0.05 & $0.02(0.03)$ & .511 & & -0.01 & $-0.01(0.04)$ & .781 \\
\hline Child sex & & -0.13 & $-0.18(0.10)$ & .077 & & -0.13 & $-0.22(0.13)$ & .096 \\
\hline Parent education & & -0.01 & $-0.01(0.08)$ & .877 & & 0.04 & $0.05(0.11)$ & .626 \\
\hline Family income & & -0.11 & $-0.09(0.06)$ & .129 & & 0.06 & $0.06(0.08)$ & .417 \\
\hline Parent body dissatisfaction & & 0.06 & $0.04(0.05)$ & .437 & & -0.05 & $-0.04(0.06)$ & .549 \\
\hline Concern for child's weight & & -0.01 & $-0.01(0.05)$ & .871 & & $-0.20 *$ & $-0.16(0.06)$ & .011 \\
\hline Child surgency & & -0.15 & $-0.15(0.08)$ & .053 & & -0.05 & $-0.06(0.10)$ & .556 \\
\hline Child negative affectivity & & 0.06 & $0.05(0.07)$ & .472 & & 0.00 & $0.00(0.09)$ & .970 \\
\hline Child effortful control & & $0.38 * *$ & $0.50(0.10)$ & $<.001$ & & $0.25 * *$ & $0.39(0.13)$ & .002 \\
\hline Parent mindfulness & & $0.21 * *$ & $0.24(0.09)$ & .011 & & 0.12 & $0.16(0.12)$ & .179 \\
\hline
\end{tabular}

$* p<.05$

$* * p<.01$

$* * * p<.001$

Note. Each row reports results from that step. Final model $F$-statistics are reported in the text. Respondent education was recoded as $0=$ high school only or vocational training and $1=$ some university or university graduate

eating behavior (BjØrkland et al. 2019). For example, in past research (Joyce and Zimmer-Gembeck 2009), chaotic foodrelated parenting was associated with children's elevated disinhibited eating. Moreover, chaotic parenting was also associated with more restrictive feeding practices, and other research has reported that restrictive feeding practices are associated with child obesity (Rollins et al. 2014, 2015).

\section{Children's Temperament}

Bivariate correlations supported our other two hypotheses, showing that children's negative affectivity and effortful control, but not surgency, were temperamental features of reactivity and regulation associated with food-related parenting. When parents reported their children were higher in effortful control, they reported more food-related supportiveness and structure, whereas when parents reported that their children were higher in negative affectivity, they endorsed more food-related parenting coerciveness and chaos. Further, some of these associations remained significant in the multivariate models. In particular, effortful control, a temperamental characteristic that is closely linked to children's selfregulation and often described as important to attentional control (Derryberry et al. 2003; Rothbart et al. 2011), was associated with more positive food-related parenting, including parents' reporting more supportiveness and more structure, even 
Table 3 Unique associations of negative food-related parenting with child temperament and parental mindfulness $(N=167)$

\begin{tabular}{|c|c|c|c|c|c|c|c|c|}
\hline & \multicolumn{4}{|c|}{ Parent coerciveness } & \multicolumn{4}{|c|}{ Parent chaos } \\
\hline & $\Delta R^{2}$ & $\beta$ & $B(\mathrm{SE} B)$ & $p$ value & $\Delta R^{2}$ & $\beta$ & $B(\mathrm{SE} B)$ & $p$ value \\
\hline Step 1 & 0.06 & & & & $0.09 *$ & & & \\
\hline Child age & & -0.11 & $-0.07(0.05)$ & .166 & & 0.07 & $0.04(0.05)$ & .350 \\
\hline Child sex & & -0.05 & $-0.10(0.16)$ & .512 & & -0.04 & $-0.07(0.14)$ & .640 \\
\hline Parent education & & 0.02 & $0.03(0.13)$ & .835 & & -0.02 & $-0.03(0.12)$ & .788 \\
\hline Family income & & 0.08 & $0.09(0.09)$ & .337 & & -0.08 & $-0.09(0.09)$ & .281 \\
\hline Parent body dissatisfaction & & $0.21 * *$ & $0.18(0.07)$ & .009 & & $0.20 * *$ & $0.16(0.06)$ & .009 \\
\hline Concern for child's weight & & 0.03 & $0.02(0.07)$ & .753 & & $0.16^{*}$ & $0.13(0.07)$ & .043 \\
\hline Step 2 & $0.07 * *$ & & & & 0.04 & & & \\
\hline Child age & & -0.11 & $-0.07(0.05)$ & .162 & & 0.07 & $0.04(0.05)$ & .357 \\
\hline Child sex & & -0.04 & $-0.08(0.16)$ & .599 & & -0.05 & $-0.08(0.14)$ & .569 \\
\hline Parent education & & 0.05 & $0.08(0.12)$ & .548 & & -0.01 & $-0.01(0.12)$ & .905 \\
\hline Family income & & 0.12 & $0.14(0.09)$ & .133 & & -0.06 & $-0.06(0.09)$ & .462 \\
\hline Parent body dissatisfaction & & 0.15 & $0.13(0.07)$ & .048 & & $0.17 *$ & $0.13(0.06)$ & .033 \\
\hline Concern for child's weight & & -0.02 & $-0.01(0.07)$ & .844 & & 0.12 & $0.10(0.07)$ & .1118 \\
\hline Child surgency & & -0.05 & $-0.08(0.12)$ & .513 & & -0.02 & $-0.03(0.11)$ & .764 \\
\hline Child negative affectivity & & $0.25 * *$ & $0.33(0.11)$ & .002 & & $0.21 *$ & $0.25(0.10)$ & .011 \\
\hline Child effortful control & & -0.08 & $-0.15(0.15)$ & .300 & & 0.03 & $0.04(0.14)$ & .747 \\
\hline Step 3 & $0.07 * * *$ & & & & $0.14 * * *$ & & & \\
\hline Child age & & -0.07 & $-0.05(0.05)$ & .331 & & 0.12 & $0.07(0.04)$ & .090 \\
\hline Child sex & & -0.06 & $-0.11(0.15)$ & .462 & & -0.07 & $-0.12(0.13)$ & .368 \\
\hline Parent education & & 0.06 & $0.10(0.12)$ & .406 & & 0.01 & $0.02(0.11)$ & .862 \\
\hline Family income & & 0.11 & $0.13(0.09)$ & .136 & & -0.07 & $-0.07(0.08)$ & .362 \\
\hline Parent body dissatisfaction & & 0.07 & $0.06(0.07)$ & .402 & & 0.04 & $0.03(0.06)$ & .583 \\
\hline Concern for child's weight & & -0.03 & $-0.02(0.07)$ & .740 & & 0.11 & $0.09(0.06)$ & .129 \\
\hline Child surgency & & -0.01 & $-0.02(0.11)$ & .883 & & 0.03 & $0.05(0.10)$ & .651 \\
\hline Child negative affectivity & & $0.18^{*}$ & $0.24(0.11)$ & .027 & & 0.10 & $0.13(0.09)$ & .184 \\
\hline Child effortful control & & -0.02 & $-0.04(0.15)$ & .775 & & 0.11 & $0.19(0.13)$ & .140 \\
\hline Parent mindfulness & & $-0.31 * *$ & $-0.51(0.14)$ & $<.001$ & & $-0.44 * *$ & $-0.66(0.12)$ & $<.001$ \\
\hline
\end{tabular}

$* p<.05$

$* * p<.01$

$* * * p<.001$

Note. Each row reports results from that step. Final model $F$-statistics are reported in the text. Respondent education was recoded as $0=$ high school only or vocational training and $1=$ some university or university graduate

after considering parents' mindfulness and other measures (i.e., parents' body dissatisfaction, concern about child's weight, and child age and sex). In contrast, negative affectivity, a temperamental characteristic often linked with elevated difficult and disruptive behaviors in children (Dich et al. 2015; Rothbart 2011), was associated with more negative foodrelated parenting, including more coerciveness and more chaotic practices, but the association with parental feeding-related chaos was significant only prior to entering parents' dispositional mindfulness into the model and the association with coerciveness was weak in step 3 of the multivariate model.

Although some associations were modest in size, our findings converge with past research that finds children's capacity for regulation and their heightened reactivity are positive or negative predictors of eating problems (Godefroy et al. 2016) and weight gain (Sutin et al. 2017). Our findings also suggest that children's temperament is associated with parents' foodrelated behaviors in somewhat specific ways. Effortful control, which is the temperamental feature considered the most closely linked to self-regulation and positive adjustment, was associated with more positive parenting but was not significantly associated with less negative food-related parenting. Conversely, probably the most challenging aspect of child temperament measured here - negative affectivity — was associated with more negative parenting, but was not associated with less positive food-related parenting. Given that effortful 
control has been found to be a correlate of self-regulation across multiple domains (Rothbart 2011), children higher in effortful control are also likely to have a greater capacity to regulate their own eating and other food-related behaviors compared with other children. For example, children high in effortful control may be more capable of delaying gratification or balancing personal desires against others' desires; they might also be easier to distract from desired foods that are not made available to them. This potentially allows parents to engage in warmer food-related interactions with their children, but this might not necessarily mean these parents are less coercive or chaotic at times. Instead, their coercive or chaotic food-related parenting behaviors may depend on other factors, such as negative affectivity, but also parents' own mindfulness or regulatory ability.

In support of the above and in contrast to findings for effortful control, children who were reported to exhibit more negative affectivity have parents that feel they need to revert to more frequent coercive parenting practices and may find it more challenging to avoid chaotic and unpredictable foodrelated parenting practices, such as changing mealtimes or relaxing guidelines, eating plans or rules. However, it is not necessarily the case that children who are more negative in affectivity will have parents who report they are less supportive or structured in the domain of food and feeding behaviors - again, this may depend on parents' own capacity for mindfulness or other characteristics (such as their concern about their child's weight, as we found here).

The associations between children's temperament and food-related parenting should be considered along with the acknowledgement that there was overlap between parents' reports of children's temperament and of their own mindfulness. In particular, parents who reported more mindfulness reported that their children were higher in effortful control and displayed less negative affectivity. Thus, children with "easier" temperamental traits have parents who endorse that they are more mindful, which could suggest that mindful parents are better able to socialize adaptive emotion and selfregulation in their children, as has been described in theory and found in previous research (Kirby 2016; Parent et al. 2016). Yet, this finding might also be used to argue that having young children with certain temperamental traits makes it easier for some parents to develop and practice mindfulness, that parents who are more mindful are more aware of their children's temperament, or that mindfulness is a personality trait that drives both parenting practices and children's temperament. Such possibilities, as well as the possibility of complex directional and mediational pathways linking parents' characteristics like mindfulness, child temperament, and parenting behaviors (as well as children's eating behaviors) over time, are certainly areas for future cross-sectional and longitudinal research, and future research that moves beyond our reliance on only parent report of all measures.

\section{Parents' Body Dissatisfaction and Concerns About Child Weight}

We also considered parent body dissatisfaction and concerns about child weight, given their known links to child obesity and weight in previous research (e.g., Blisset and Haycraft 2008; Gouvela et al., 2018). Parents' dissatisfaction about their own bodies and their concerns about child weight were each associated with food-related parenting practices in the bivariate correlations. Yet, only one unique association was found in our multivariate models at step 3. This association was between parents' concern for child weight and parents' reduced provision of foodrelated structure. Given evidence that concern for child's weight is related to actual child weight (Gregory et al. 2010), this suggests that child weight may play some direct role in parenting related to food even after considering other child and parent factors that may be important for explaining parenting behavior. What is important to note is that this association between parents' concerns about child weight and food-related parenting structure was negative; thus, parents who were more concerned also tended to report less structure. Structure included items such as setting expectations about healthy eating for children and having some family guidelines for eating, meals, and snack times. It could be that concern interferes with parents' ability to provide structure and results in their greater avoidance of setting rules; in other words, parents who are more worried about their children relax rules and find it more difficult to provide structure around preparing and providing food. More broadly, research shows that cognitive-emotional parenting processes, such as parenting stress and worry about one's child, are linked with inconsistent parenting (Shea and Coyne 2011) and dysfunctional parenting practices (Pinderhughes et al. 2000). Indeed, one of these studies showed that experiential avoidance of distress and stress may interfere with parents' ability to implement discipline strategies consistently (Shea and Coyne 2011). Alternatively, multiple items focused on the entire family, rather than children only, and we did not measure other family demographics, such as family size. Therefore, it is possible that challenges with consistency in healthy eating among the entire family results in eating behaviors that lead parents to have greater concerns about their children's weight. For example, when families spend less time scheduling and planning family meals, they are more likely to have overweight children (Fiese et al. 2012). These findings suggest a pathway with food-related parenting related to increasing parenting concern about children's weight, rather than the reverse of parents' concern about children's weight as a predictor of food-related parenting. These opposing directional pathways could be tested in future research. 


\section{Limitations and Future Research}

There are five limitations of this study to mention. First, there was no assessment of parent and child weight, although we did include measures of parents' body dissatisfaction and parents' concern about child weight as markers of weight issues and concerns in each family. Future research could include a specific assessment of parent and child weight, body mass index, and waist circumference which could add to this research. Second, the cross-sectional design relying on selfreport from parents limits interpretation of the direction of associations and may have inflated associations due to shared method variance. In future research, the role of mindfulness and mindful parenting in the child feeding and eating context on parenting and children's behavior could be tested within an experimental or longitudinal design, after considering parent and child body mass.

Third, the participant demographics could limit generalizability of the findings. It would be beneficial to access a sample with more diversity in terms of education, income, and sociocultural background to provide more confidence in the generalizability of the results. Fourth, previous studies have shown that food-related parenting can moderate the association between the more specific behavior of restrictive feeding practices and child BMI, and that the relationship between restriction and child disinhibited eating depends upon the parent's food-related parenting (supportive, coercive, or chaotic; Hennessy et al. 2010; Joyce and Zimmer-Gembeck 2009). Future research might test the role of parents' mindfulness in these processes, incorporating multiple aspects of food-related parenting and specific parenting behaviors, such as restrictiveness, as correlates of children's eating behaviors and weight. Fifth and finally, we did not include a measure of parent mental health or parent perceived stress. These difficulties could be associated with mindfulness and could explain why mindfulness is associated with food-related parenting.

In summary, we focused on parents' dispositional mindfulness as a correlate of food-related parenting. Unique relationships were found between parental dispositional mindfulness and three aspects of food-related parenting practices after accounting for children's temperament, parents' concerns about their children's weight, parents' own body dissatisfaction, parents' education and income, and child age and sex. Children's temperament was also a correlate of food-related parenting, with positive temperamental traits associated with more positive food-related parenting and negative temperamental traits associated with more negative food-related parenting. Future research should examine bidirectional pathways to better isolate the direction of effects and pinpoint potential intervention targets.

Author Contributions MZ-G led the study design, conducted all analyses for the publication, and led the writing of the article for publication. AM collaborated on the study design, collected and entered all data, conducted preliminary analyses, and drafted parts of the article for publication. HW assisted with literature searching, interpretation of findings, and the writing of the article for publication.

\section{Compliance with Ethical Standards}

Ethical approval All procedures performed were in accordance with the ethical standards of the Griffith University Human Research Ethics Committee and with the 1964 Helsinki declaration and its later amendments or comparable ethical standards.

Informed Consent Informed consent was obtained from all participants in this study.

Conflict of Interest The authors declare that they have no conflict of interest.

\section{References}

Anzman-Frasca, S., Stifter, C. A., \& Birch, L. L. (2012). Temperament and childhood obesity risk: a review of the literature. Journal of Developmental and Behavioral Pediatrics, 33, 733-745. https:// doi.org/10.1097/DBP.0b013e31826a119f.

Ashcroft, J., Semmler, C., Carnell, S., van Jaarsveld, C. H. M., \& Wardle, J. (2008). Continuity and stability of eating behaviour traits in children. European Journal of Clinical Nutrition, 62(8), 985-990. https://doi.org/10.1038/sj.ejcn.1602855.

Australian Bureau of Statistics. (2015). Australian demographic statistics. Retrieved on 13 March 2019 from http://www.abs.gov. au/ausstats/abs@.nsf/lookup/3101.0Media\%20Release1Dec\% 202015

Baer, R., Smith, G. T., Hopkins, J., Krietemeyer, J., \& Toney, L. (2006). Using self-report assessment methods to explore facets of mindfulness. Assessment, 13, 27-45. https://doi.org/10.1177/ 1073191105283504.

Birch, L. L., Fisher, J. O., Grimm-Thomas, K., Markey, C. N., Sawyer, R., \& Johnson, S. L. (2001). Confirmatory factor analysis of the child feeding questionnaire: a measure of parental attitudes, beliefs and practices about child feeding and obesity proneness. Appetite, 36, 201-210. https://doi.org/10.1006/appe.2001.0398.

BjØrkland, O., WichstrØm, L., Llewellyn, C. H., \& Steinsbekk, S. (2019). Emotional over- and undereating in children: a longitudinal analysis of child and contextual predictors. Child Development. https://doi.org/10.1111/cdev.13110.

Black, M. M., \& Aboud, F. E. (2011). Responsive feeding is embedded in a theoretical framework of responsive parenting. The Journal of Nutrition, 141, 490-494. https://doi.org/10.3945/jn.110.129973.

Blisset, J., \& Haycraft, E. (2008). Are parenting style and controlling feeding practices related? Appetite, 50, 477-485. https://doi.org/10. 1016/j.appet.2007.10.003.

Blissett, J., Meyer, C., \& Haycraft, E. (2006). Maternal and paternal controlling feeding practices with male and female children. Appetite, 47, 212-219. https://doi.org/10.1016/j.appet.2006.04.002.

Bögels, S., \& Restifo, K. (2014). Mindful parenting: a guide for mental health practitioners. NY: Springer.

Boles, R. E., Reiter-Purtill, J., \& Zeller, M. H. (2013). Persistently obese youth: Interactions between parenting styles and feeding practices with child temperament. Clinical Pediatrics, 52, 1098-1106. https:// doi.org/10.1177/0009922813497091.

Chiang, E. S., \& Padilla, M. A. (2012). Assessment of parent orientation towards autonomy vs. control in promoting children's healthy eating 
and exercise. Applied Psychology: Health and Well-being, 4, 202 217. https://doi.org/10.1111/j.1758-0854.2012.01069.x.

Coatsworth, J. D., Duncan, L. G., Nix, R. L., Greenberg, M. T., Jochebed, G. G., Bamberger, K. T., Berrena, E., \& Demi, M. A. (2015). Integrating mindfulness with parent training: effects of the mindfulness-enhanced strengthening families program. Developmental Psychology, 51, 26-35. https://doi.org/10.1037/ a0038212.

Darling, N., \& Steinberg, L. (1993). Parenting style as context: an integrative model. Psychological Bulletin, 113, 487-496. https://doi. org/10.1037/0033-2909.113.3.487.

De Onis, M., Blössner, M., \& Borghi, E. (2010). Global prevalence and trends of overweight and obesity among preschool children. American Journal of Clinical Nutrition, 92, 1257-1264. https:// doi.org/10.3945/ajen.2010.29786.

Deater-Deckard, K., Chen, N., Wang, Z., \& Bell, M. A. (2012). Socioeconomic risk moderates the link between household chaos and maternal executive function. Journal of Family Psychology, 26, 391-399. https://doi.org/10.1037/a0028331.

Deci, E. L., \& Ryan, R. M. (1985). Intrinsic motivation and selfdetermination in human behavior. NY: Plenum Press.

DeCosta, P., Moller, P., Frost, M. B., \& Olsen, A. (2017). Changing children's eating behaviour: a review of experimental research. Appetite, 113, 327-357. https://doi.org/10.1016/j.appet.2017.03. 004.

Derryberry, D., Reed, M. A., \& Pilkenton-Taylor, C. (2003). Temperament and coping: Advantages of an individual differences perspective. Development and Psychopathology, 15, 1049-1066. https://doi.org/10.1017/S0954579403000439.

Dich, N., Doan, S., \& Evans, G. (2015). Children's negative emotionality combined with poor self-regulation affects allostatic load in adolescence. International Journal of Behavioral Development, 39, 368 375. https://doi.org/10.1177/0165025414544232.

Dijkstra, P., \& Barelds, D. P. H. (2011). Examining a model of dispositional mindfulness, body comparison, and body satisfaction. Body Image, 8, 419-422. https://doi.org/10.1016/j.bodyim.2011.05.007.

Dumas, J. E. (2005). Mindfulness-based parent training: strategies to lessen the grip of automaticity in families with disruptive children. Journal of Clinical Child and Adolescent Psychology, 34, 779-791. https://doi.org/10.1207/s15374424jccp3404_20.

Fiese, B. H., Hammons, A., \& Grigsby-Toussaint, D. (2012). Family mealtimes: a contextual approach to understanding childhood obesity. Economics and Human Biology, 10, 365-374. https://doi.org/ 10.1016/j.ehb.2012.04.004.

Frankel, L. A., Powell, E., \& Jansen, E. (2018). The relationship between structure-related food parenting practices and children's heightened levels of self-regulation in eating. Childhood Obesity, 14, 81-88. https://doi.org/10.1089/chi.2017.0164.

Garner, D. M., Olmstead, M. P., \& Polivy, J. (1983). Development and validation of a multidimensional eating disorder inventory for anorexia nervosa and bulimia. International Journal of Eating Disorders, 2, 15-34. https://doi.org/10.1002/1098-108X(198321) 2:2<15::AID-EAT2260020203>3.0.CO;2-6.

Girelli, L., Hagger, M. S., Mallia, L., \& Lucidi, F. (2016). From perceived autonomy support to intentional behaviour: testing an integrated model in three healthy eating behaviours. Appetite, 96, 280-292. https://doi.org/10.1016/j.appet.2015.09.027.

Godefroy, V., Trinchera, L., Romo, L., \& Rigal, N. (2016). Modelling the effect of temperament on BMI through appetite reactivity and selfregulation in eating: a structural equation modelling approach in young adolescents. International Journal of Obesity, 40, 573-580. https://doi.org/10.1038/ijo.2016.6.

Gouvela, M. J., Canavarro, M. C., \& Moreira, H. (2019). The role of mindful parenting and children's weight in mothers' child-feeding practices. Eating and Weight Disorders. https://doi.org/10.1007/ s40519-018-0615-x.
Gouvela, M. J., Canavarro, M. C., \& Moreira, H. (2018). Is mindful parenting associated with adolescents' emotional eating? The mediating role of adolescents' self-compassion and body shame. Frontiers in Psychology, 9: 2004. https://doi.org/10.3389/fpsyg. 2018.02004

Gregory, J. E., Paxton, S. J., \& Brozovic, A. M. (2010). Pressure to eat and restriction are associated with child eating behaviours and maternal concern about child weight, but not child body mass index, in 2- to 4-year-old children. Appetite, 54, 550-556. https://doi.org/10. 1016/j.appet.2010.02.013.

Grolnick, W. S., Deci, E. L., \& Ryan, R. M. (1997). Internalization within the family: the Self-Determination Theory perspective. In J. E. Grusec \& L. Kuczynski (Eds.), Parenting and children's internalization of values: Handbook of contemporary theory (pp. 135-161). NY: Wiley.

Hambour, V. K., Zimmer-Gembeck, M. J., Clear, S., Rowe, S., \& Avdagic, E. (2018). Emotion regulation and mindfulness in adolescents: conceptual and empirical connection and associations with social anxiety symptoms. Personality and Individual Differences, 134, 7-12. https://doi.org/10.1016/j.paid.2018.05.037.

Harnett, P. H., \& Dawe, S. (2012). The contribution of mindfulness-based therapies for children and families and proposed conceptual integration. Child and Adolescent Mental Health, 17, 195-208. https://doi. org/10.1111/j.1475-3588.2011.00643.x.

Haszard, J. J., Russell, C. G., Byrne, R. A., Taylor, R. W., \& Campbell, K. J. (2019). Early maternal feeding practices: associations with overweight later in childhood. Appetite, 132, 91-96. https://doi.org/10. 1016/j.appet.2018.10.008

Haycraft, E., Farrow, C., Meyer, C., Powell, F., \& Blissett, J. (2011). Relationships between temperament and eating behaviours in young children. Appetite, 56, 689-692. https://doi.org/10.1016/j.appet. 2011.02.005

Hendy, H., \& Williams, K. (2012). Mother's feeding practices for children 3-10 years of age and their associations with child demographics. Appetite, 58, 710-716. https://doi.org/10.1016/j.appet. 2012.01.011.

Hennessy, E., Hughes, S. O., Goldberg, J. P., Hyatt, R. R., \& Economos, C. D. (2010). Parent behaviour and weight status among a diverse group of underserved rural families. Appetite, 54, 369-377. https:// doi.org/10.1016/j.appet.2010.01.004.

Johnson, B. J., Bell, L. K., Zarnowiecki, D., Rangan, A. M., \& Golley, R. K. (2017). Contribution of discretionary foods and drinks to Australian children's intake of energy, saturated fat, added sugars and salt. Children (Basel, Switzerland), 4, 104. https://doi.org/10. 3390/children4120104.

Joussemet, M., Landry, R., \& Koestner, R. (2008). A Self-Determination Theory perspective on parenting. Canadian Psychology/ Psychologie Canadienne, 49, 194-200. https://doi.org/10.1037/ a0012754.

Joyce, J., \& Zimmer-Gembeck, M. J. (2009). Parent feeding restriction and child weight. The mediating role of child disinhibited eating and the moderating role of the parenting context. Appetite, 52, 726-734. https://doi.org/10.1016/j.appet.2009.03.015.

Kabat-Zinn, J. (2003). Mindfulness-based interventions in context: past, present and future. Clinical Psychology: Science and Practice, 10, 144-156. https://doi.org/10.1093/clipsy/bpg016.

Keng, S. L., Smoski, M. J., \& Robins, C. J. (2011). Effects of mindfulness on psychological health: a review of empirical studies. Clinical Psychology Review, 31, 1041-1056. https://doi.org/10.1016/j.cpr. 2011.04.006.

Kirby, J. N. (2016). The role of mindfulness and compassion in nurturing family environments. Clinical Psychology: Science and Practice, 23, 142-157. https://doi.org/10.1111/cpsp.12149.

Krebs-Smith, S. M., Guenther, P. M., Subar, A. F., Kirkpatrick, S. I., \& Dodd, K. W. (2010). Americans do not meet federal dietary 
recommendations. Journal of Nutrition, 140, 1832-1838. https:// doi.org/10.3945/jn.110.124826.

Leung, C. Y. Y., Lumeng, J. C., Kaciroti, N. A., Chen, Y. P., Rosenblum, K., \& Miller, A. L. (2014). Surgency and negative affectivity, but not effortful control, are uniquely associated with obesogenic eating behaviors among low-income pre-schoolers. Appetite, 78, 139146. https://doi.org/10.1016/j.appet.2014.03.025.

Lopez, N. V., Schembre, S., Belcher, B. R., O'Connor, S., Maher, J. P., Arbel, R., Margolin, G., \& Dunton, G. F. (2019). Parenting styles, food-related parenting practices, and children's healthy eating: a mediation analysis to examine relationships between parenting and child diet. Appetite, 128, 205-213. https://doi.org/10.1016/j.appet. 2018.06.021.

Mitchell, G. L., Farrow, C., Haycraft, E., \& Meyer, C. (2013). Parental influences on children's eating behaviour and characteristics of successful parent-focussed interventions. Appetite, 60, 85-94. https:// doi.org/10.1016/j.appet.2012.09.014.

Ng, J. Y. Y., Ntoumanis, N., ThØgersen-Ntoumani, C., Deci, E. L., Ryan, R. M., Duda, J., \& Williams, G. C. (2012). Self-determination theory applied to health contexts: a meta-analysis. Perspectives on Psychological Science, 7, 325-340. https://doi.org/10.1177/ 1745691612447309.

Parent, J., McKee, L. J., Rough, J. N., \& Forehand, R. (2016). The association of parent mindfulness with parenting and youth psychopathology across three developmental stages. Journal of Abnormal Child Psychology, 44, 191-202. https://doi.org/10.1007/s10802015-9978-x.

Pepping, C. A., O'Donovan, A., \& Davis, P. J. (2013). The positive effects of mindfulness on self-esteem. The Journal of Positive Psychology, 8, 376-386. https://doi.org/10.1080/17439760.2013. 807353

Pepping, C. A., O'Donovan, A., Zimmer-Gembeck, M. J., \& Hanisch, M. (2015). Individual differences in attachment eating pathology: the mediating role of mindfulness. Personality and Individual Differences, 75, 24-29. https://doi.org/10.1016/j.paid.2014.10.040.

Pieper, J. R., \& Laugero, K. D. (2013). Preschool children with lower executive function may be more vulnerable to emotional-based eating in the absence of hunger. Appetite, 62, 103-109. https://doi.org/ 10.1016/j.appet.2012.11.020.

Pinderhughes, E. E., Dodge, K. A., Bates, J. E., Pettit, G. S., \& Zelli, A. (2000). Discipline responses: influences of parents' socioeconomic status, ethnicity, beliefs about parenting, stress, and cognitiveemotional processes. Journal of Family Psychology, 14, 380-400. https://doi.org/10.1037/0893-3200.14.3.380.

Putman, S. P., \& Rothbart, M. K. (2006). Development of short and very short forms of the Children's Behavior Questionnaire. Journal of Personality Assessment, 87, 102-112. https://doi.org/10.1207/ s15327752jpa8701_09.

Roemer, L., Williston, S. K., \& Rollins, L. G. (2015). Mindfulness and emotion regulation. Current Opinion in Psychology, 3, 52-57. https://doi.org/10.1016/j.copsyc.2015.02.006.

Rollins, B. Y., Loken, E., Savage, J. S., \& Birch, L. L. (2014). Effects of restriction on children's intake differ by temperament, food reinforcement, and parent's chronic use of restriction. Appetite, 73, 31-39. https://doi.org/10.1016/j.appet.2013.10.005.

Rollins, B. Y., Savage, J. S., Fisher, J. O., \& Birch, L. L. (2015). Alternatives of restrictive feeding practices to promote selfregulation in childhood: a developmental perspective. Pediatric Obesity, 11, 326-332. https://doi.org/10.1111/ijpo.12071.

Rothbart, M. K. (2007). Temperament, development, and personality. Current Directions in Psychological Science, 16, 207-212.

Rothbart, M. K. (2011). Becoming who we are: temperament, personality and development. NY: Guilford Press.

Rothbart, M. K., Ahadi, S. A., \& Evans, D. E. (2000). Temperament and personality: origins and outcomes. Journal of Personality and
Social Psychology, 78, 122-135. https://doi.org/10.1037/00223514.78.1.122.

Rothbart, M. K., Sheese, B. E., Rueda, M. R., \& Posner, M. I. (2011). Developing mechanisms of self-regulation in early life. Emotion Review, 3, 207-213. https://doi.org/10.1177/1754073910387943.

Ryan, R. M., \& Deci, E. L. (2000). Self-determination theory and the facilitation of intrinsic motivation, social development, and wellbeing. American Psychologist, 55, 68-78. https://doi.org/10.1037/ 0003-066X.55.1.68.

Shea, S. E., \& Coyne, L. W. (2011). Maternal dysphoric mood, stress, and parenting practices in mothers of head start preschoolers: the role of experiential avoidance. Child \& Family Behavior Therapy, 33, 231247. https://doi.org/10.1080/07317107.2011.596004.

Shloim, N., Edelson, L. R., Martin, N., \& Hetherington, M. M. (2015). Parenting styles, feeding styles, feeding practices, and weight status in 4-12 year-old children: A systematic review of the literature. Frontiers in Psychology, 6, Article 1849. https://doi.org/10.3389/ fpsyg.2015.01849.

Singh, N. N., Singh, A. N., Lancioni, G. E., Singh, J., Winton, A. S. W., \& Adkins, A. D. (2010). Mindfulness training for parents and their children with ADHD increases children's compliance. Journal of Child and Family Studies, 19, 157-166. https://doi.org/10.1007/ s10826-009-9272-z.

Skinner, E., Johnson, S., \& Snyder, T. (2005). Six dimensions of parenting: a motivation model. Parenting: Science and Practice, 5, 175235. https://doi.org/10.1207/s15327922par0502 3 .

Sleddens, E. F. C., Kremers, S. P. J., Stafleu, A., Dagnelie, P. C., De Vries, N. K., \& Thijs, C. (2014). Food parenting practices and child dietary behavior: prospective relations and the moderating role of general parenting. Appetite, 79, 42-50. https://doi.org/10.1016/j.appet.2014. 04.004 .

Sutin, A. R., Kerr, J. A., \& Terracciano, A. (2017). Temperament and body weight from ages 4 to 15 years. International Journal of Obesity, 41, 1056-1061. https://doi.org/10.1038/ijo.2017.62.

Tabachnick, B. G., \& Fidell, L. S. (2001). Using multivariate statistics (4th ed.). Boston, MA: Allyn and Bacon.

Tan, C. C., \& Holob, S. (2011). Children's self-regulation in eating. Associations with inhibitory control and parents' feeding behaviours. Journal of Paediatric Psychology, 36, 340-345. https://doi. org/10.1093/jpepsy/jsq089.

Taren, A. A., Creswell, J. D., \& Gianaros, P. J. (2013). Dispositional mindfulness co-varies with smaller amygdala and caudate volumes in community adults. PLOS one, 8, e64574. https://doi.org/10.1371/ journal.pone.0064574.

U.S. Department of Health and Human Services and U.S. Department of Agriculture. 2015-2020 Dietary Guidelines for Americans. 8th Edition. December 2015. Available at http://health.gov/ dietaryguidelines/2015/guidelines/.

Vaughn, A. E., Ward, D. S., Fisher, J. O., Faith, M. S., Hughes, S. O., Kremers, S. P., et al. (2016). Fundamental constructs in food parenting practices: a content map to guide future research. Nutrition Reviews, 74, 98-117. https://doi.org/10.1093/nutrit/nuv061.

Ventura, A., \& Birch, L. L. (2008). Does parenting affect children's eating and weight status? International Journal of Behavioral Nutrition and Physical Activity, 5, 15. https://doi.org/10.1186/1479-5868-515.

Vollmer, R. L., \& Mobley, A. R. (2013). Parenting styles, feeding styles, and their influence on child obesogenic behaviors and body weight. A review. Appetite, 71, 232-241. https://doi.org/10.1016/j.appet. 2013.08.015.

Von Suchodoletz, A., Trommsdorff, G., \& Heikamp, T. (2011). Linking maternal warmth and responsiveness to children's self-regulation. Social Development, 20, 486. https://doi.org/10.1111/j.1467-9507. 2010.00588.x.

Wanden-Berghe, R. G., Sanz-Valero, J., \& Wanden-Berghe, C. (2010). The application of mindfulness to eating disorders treatment: a 
systematic review. Eating Disorders, 19, 34 48. https://doi.org/10. 1080/10640266.2011.533604.

Webb, H. J., Zimmer-Gembeck, M. J., Scuffham, P. A., Scott, R., \& Barber, B. (2018). Family stress predicts poorer dietary quality in children: examining the role of the parent-child relationship. Infant and Child Development, 27. https://doi.org/10.1002/icd.2088.

Yavuz, H. M., \& Selcuk, B. (2018). Predictors of obesity and overweight in pre-schoolers: the role of parenting styles and feeding practices. Appetite, 120, 491-499. https://doi.org/10.1016/j.appet.2017.10. 001.

Zimmer-Gembeck, M. J., Joyce, J., Kerin, J., Webb, H., Morrissey, S., \& McKay, A. (2019a). Self-determination theory and food-related parenting: the Parent Socioemotional Context of Feeding
Questionnaire. Journal of Family Psychology, 33, 476-486. https://doi.org/10.1037/fam0000524.

Zimmer-Gembeck, M. J., Kerin, J., Webb, H. J., Gardner, A., Mastro, S., \& Swan, K. (2019b). Improved perceptions of emotion regulation and reflective functioning in parents: two additional positive outcomes of Parent-Child Interaction Therapy. Behavior Therapy, 50, 340-352. https://doi.org/10.1016/j.beth.2018.07.002.

Publisher's Note Springer Nature remains neutral with regard to jurisdictional claims in published maps and institutional affiliations. 